\title{
PRODUÇÃO DE SILAGEM DE HÍBRIDOS DE MILHO E SORGO SEM NITROGÊNIO DE COBERTURA EM SAFRA DE VERÃO ${ }^{1}$
}

\author{
Roni Fernandes Guareschi², Rafaella Belchior Brasil ${ }^{2}$, Adriano Perin ${ }^{2}$, Jessika Mara Martins Ribeiro ${ }^{2}$
}

\section{ABSTRACT \\ MAIZE AND SORGHUM HYBRIDS SILAGE \\ PRODUCTION WITHOUT NITROGEN FERTILIZATION IN THE SUMMER GROWING SEASON}

Obtaining hybrids that have high percentage of grains in total dry mass, more digestible leaves and stems, and high total dry matter yield is the main objective of silage breeding programs. So, the objective of this research was to evaluate the silage production of hybrid maize and sorghum whole plants without nitrogen fertilization, in the summer growing season. The research was conducted in a medium textured Latossol, in Rio Verde, southeast of the Goiás State, Brazil. A randomized blocks design with six treatments and four replications was used. The treatments were maize (P-30F90, DKB-177, and AG-7010) and sorghum (Experimental 1, Experimental 2, and Volumax). For maize, six plants per meter were sown at $0.90 \mathrm{~m}$ row spacing, while, for sorghum, eight plants per meter were sown at $0.45 \mathrm{~m}$ row spacing. The evaluations consisted of shoot biomass, as well as ratio of fresh and dry mass of maize stalks, leaves, and ears, and sorghum panicles, collected at 105 days after emergence (DAE). The Volumax sorghum hybrid presented the highest shoot biomass yield. Maize hybrids presented a higher proportion of ear/shoot biomass than panicle/shoot biomass of sorghum hybrids, confirming the importance of corn use for silage quality.

KEY-WORDS: Zea mays; Sorghum bicolor; plant characteristics.

\section{INTRODUÇÃO}

O milho tem sido a forrageira de maior utilização no processo de ensilagem, entretanto, o sorgo tem se apresentado como boa opção em substituição ao milho, principalmente devido à maior resistência a veranicos, maior produção por área e menor exigência quanto à fertilidade do solo (Dias et al. 2001).

A silagem de milho possui boa produção de massa por unidade de área cultivada (Neumann et al. 2003) e elevado conteúdo energético (Rocha et al. 2006). Já a silagem de sorgo destaca-se por ser um

\section{RESUMO}

A obtenção de híbridos que apresentem elevada participação de grãos na massa seca total, colmos e folhas mais digestíveis e alta produtividade total de massa seca é o principal objetivo dos programas de melhoramento visando à ensilagem. Diante disto, o objetivo deste trabalho foi avaliar a produção de silagem de planta inteira de híbridos de milho e sorgo, na safra de verão, sem adubação nitrogenada de cobertura. A pesquisa foi conduzida em Latossolo Vermelho distroférrico de textura média, no município de Rio Verde, sudoeste de Goiás. Adotouse o delineamento de blocos ao acaso, com seis tratamentos e quatro repetições. Os tratamentos foram milho (P-30F90, DKB-177 e AG-7010) e sorgo (experimental 1, experimental 2 e Volumax). O milho foi semeado em espaçamento de $0,90 \mathrm{~m}$, com 6 plantas por metro, e o sorgo em espaçamento de $0,45 \mathrm{~m}$, com 8 plantas por metro. As avaliações constaram da produção de biomassa da parte aérea, bem como da proporção de massa fresca e seca de colmo, folhas e espigas de milho e panículas de sorgo, aos 105 dias após a emergência (DAE). O híbrido de sorgo Volumax apresentou a maior produtividade de biomassa, para fins de ensilagem. Os híbridos de milho conferiram maior proporção de espigas, na relação espigas/biomassa total, quando comparados à relação panículas/biomassa total dos híbridos de sorgo, demonstrando a importância da utilização de milho para agregar qualidade à silagem.

PALAVRAS-CHAVE: Zea mays; Sorghum bicolor; características fitotécnicas.

alimento de alto valor nutritivo, que apresenta alta concentração de carboidratos solúveis, essenciais para adequada fermentação lática, altos rendimentos de massa seca por unidade de área (Neumann et al. 2002a) e apresenta, em média, $85 \%$ a $90 \%$ do valor nutritivo das silagens de milho (Zago 1997).

A obtenção de híbridos que apresentem elevada participação de grãos na massa seca total, colmos e folhas mais digestíveis e alta produtividade total de massa seca é o principal objetivo dos programas de melhoramento visando à ensilagem. Desta forma, a escolha das gramíneas forrageiras e da cultivar para

1. Trabalho recebido em jun./2009 e aceito para publicação em dez./2010 (n registro: PAT 6389/ DOI: 10.5216/pat.v40i4.6389).

2. Instituto Federal de Educação, Ciência e Tecnologia, Campus Rio Verde, Rio Verde, GO. E-mails: roniguareschi@gmail.com, rafaellabelchior@hotmail.com, perinrj@yahoo.com.br, jessikarj@yahoo.com.br. 
ensilagem é um importante instrumento para o sucesso do processo (Mello 2004, Neumann et al. 2002b). Mello (2004) menciona que o sucesso na produção de silagem depende do grau de adaptação dos diferentes genótipos, frente às características edafoclimáticas da área de cultivo.

Os fatores edafoclimáticos influenciam na produção de silagem e, desta forma, a escolha de um bom híbrido constitui-se em alternativa de sucesso (Silva et al. 1999). Silagens de milho têm sido indicadas para locais de solos mais férteis, clima mais estável e com alta tecnologia, enquanto o sorgo tem sido preconizado para locais marginais de solos mais pobres, sujeitos a veranicos ou próximos a centros urbanos (Silva 2001).

A pecuária leiteira e os confinamentos do sudoeste de Goiás demandam elevada quantidade de forragem e/ou silagem de alta qualidade, no período seco do ano. Atualmente, vários híbridos de milho e sorgo estão disponíveis, com grandes variações, quanto à produção e concentração de nutrientes. Por isto, é importante desenvolver estudos comparativos, que combinem características agronômicas e nutricionais destas cultivares.

Desta forma, o objetivo do trabalho foi avaliar a produção de silagem de planta inteira de híbridos de milho e sorgo, na safra de verão, sem adubação nitrogenada de cobertura.

\section{MATERIAL E MÉTODOS}

O experimento foi conduzido em condições de campo, em Latossolo Vermelho distroférrico de textura média, na Fazenda Experimental do Instituto Federal Goiano, no município de Rio Verde $\left(20^{\circ} 45^{\prime} 53^{\prime}\right.$ 'S, $51^{\circ} 55^{\prime} 53$ "W e altitude de $748 \mathrm{~m}$ ), sudoeste de Goiás. A precipitação pluviométrica anual média é de $1.740 \mathrm{~mm}$, com clima tropical quente, estação chuvosa e seca bem definidas e relevo relativamente plano.

Foram coletadas amostras de solo da área experimental, à profundidade de $0-20 \mathrm{~cm}$, as quais foram submetidas a análise química e granulométrica, seguindo-se a metodologia descrita pela

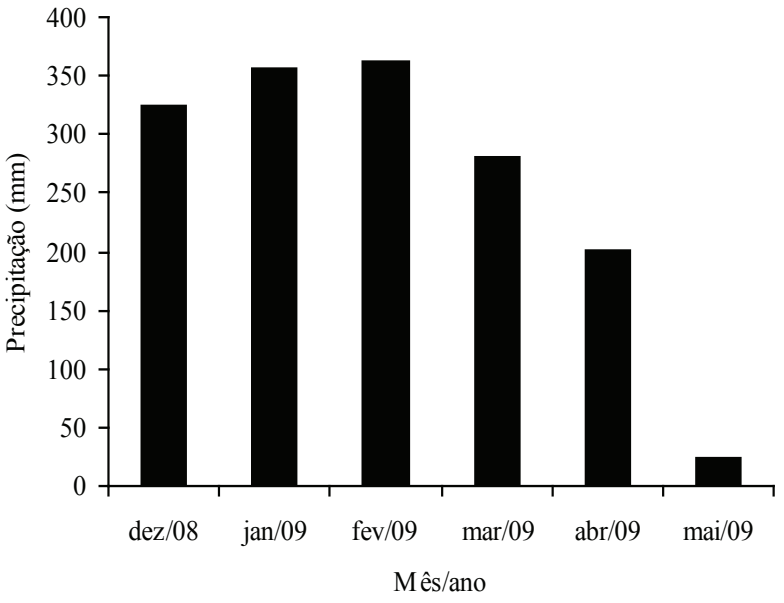

Figura 1. Precipitação pluviométrica ocorrida na área experimental (Rio Verde, GO, 2008/2009).

Embrapa (1997). Os resultados da análise química e física encontram-se na Tabela 1 e a precipitação pluviométrica, ocorrida nos meses de condução do experimento, na Figura 1.

Adotou-se o delineamento experimental em blocos ao acaso, com seis tratamentos e quatro repetições. Os tratamentos foram milho (P30F90, DKB-177 e AG-7010) e sorgo (experimental 1, experimental 2 e Volumax). As parcelas experimentais possuíam 12 fileiras de $10 \mathrm{~m}$ de comprimento, espaçadas a cada $0,90 \mathrm{~m}$, para o cultivo dos híbridos de milho (66.666 plantas ha-1), e $0,45 \mathrm{~m}$, para o cultivo do sorgo (177.777 plantas ha-1). A área útil das parcelas experimentais foi constituída por 2 fileiras de plantas centrais, com 4,0 m de comprimento. Desta forma, a área útil para os híbridos de milho foi de $7,2 \mathrm{~m}^{2}$ $(4,0 \mathrm{~m} \times 1,8 \mathrm{~m})$ e, para os híbridos de sorgo, de $3,6 \mathrm{~m}^{2}$ (4,0 $\mathrm{m} \mathrm{x} 0,9 \mathrm{~m})$.

As parcelas de milho apresentaram dimensões maiores do que as parcelas de sorgo, pelo fato de o milho ter sido semeado em espaçamento duas vezes superior ao do sorgo. Este procedimento foi adotado devido à facilidade na operação mecanizada, por ocasião da semeadura do experimento. Embora a área útil dos tratamentos de milho tenha sido superior à dos tratamentos com sorgo, os dados

Tabela 1. Análise química e granulométrica de solo da área experimental, à profundidade de 0-20 cm (Rio Verde, GO, 2008).

\begin{tabular}{|c|c|c|c|c|c|c|c|c|c|c|c|c|}
\hline Profundidade & $\mathrm{P}$ & $\mathrm{pH} \mathrm{H}_{2} \mathrm{O}$ & K & $\mathrm{Ca}$ & $\mathrm{Mg}$ & $\mathrm{H}+\mathrm{Al}$ & S & $\mathrm{T}$ & V & Areia & Silte & Argila \\
\hline $\mathrm{cm}$ & $\mathrm{mg} \mathrm{dm}^{-3}$ & & & & $-\mathrm{c}$ & $1_{c} \mathrm{dm}^{-3}-$ & & - & $\%$ & & $\mathrm{~g} \mathrm{~kg}^{-1}$ & - \\
\hline $0-20$ & 9,0 & 6,2 & 0,64 & 4,53 & 1,40 & 5,33 & 6,57 & 11,90 & 55,2 & 380,0 & 120,0 & 500,0 \\
\hline
\end{tabular}


de produção de biomassa foram convertidos em $\mathrm{Mg} \mathrm{ha}^{-1}$, para uniformizar a unidade de apresentação dos dados.

As principais características dos híbridos de milho e sorgo utilizados nesta pesquisa foram cedidas pelas empresas que os produziram: o milho da empresa Pioneer ${ }^{\circledR}$ P-30F90 é um híbrido simples, de ciclo semiprecoce, que apresenta alto potencial produtivo para grãos e silagem; o milho da Dekalb ${ }^{\circledR}$ DKB-177 é um híbrido simples, de ciclo precoce (ciclo de 130 dias); o milho da Agroceres ${ }^{\circledR}$ AG-7010 é um híbrido simples, de ciclo precoce (125 dias); e o sorgo Volumax é um híbrido da empresa Agroceres ${ }^{\circledR}$, de ciclo precoce (125 dias), que apresenta, como finalidade, a produção de grãos e silagem de planta inteira. Já os híbridos de sorgo experimental 1 e 2 são genótipos que se encontram em condições de teste para lançamento, sendo considerados materiais silageiros.

O experimento foi instalado em sucessão à cultura da soja e a área experimental apresentava baixa quantidade de resíduos da oleaginosa. A dessecação da área foi realizada em 13/12/2008, com 3,3 $\mathrm{L} \mathrm{ha}^{-1}$ de Roundup Transorb ${ }^{\circledR}$ (Glyphosate) $+0,5 \mathrm{~L} \mathrm{ha}^{-1}$ de 2,4-D (Dimetilamina). Antes da semeadura das variedades de milho e sorgo, as sementes foram tratadas com fungicida Imidacloprid ( $30 \mathrm{~g}$ do i.a.) + Thiodicarb (90 g do i.a.), na dose de $210 \mathrm{~g} \mathrm{~kg}^{-1}$ do ingrediente ativo. A semeadura mecanizada ocorreu em 16/12/2008 e as plantas emergiram seis dias após a semeadura. A semeadura se deu em sistema de plantio direto (SPD). Na ocasião, foi distribuída a adubação no sulco de semeadura, aplicando-se $250 \mathrm{~kg} \mathrm{ha}^{-1}$ do adubo formulado 08-20-18.

Não foi realizada adubação nitrogenada de cobertura, pois os híbridos experimentais de sorgo são pouco responsivos a adubação. Ademais, o objetivo deste trabalho foi produzir silagem a baixo custo, com relação ao uso de insumos, haja vista que a área apresenta níveis adequados de fertilidade e, também, é utilizada a cultura da soja, na rotação de culturas.

Não foram feitas aplicações de inseticidas e herbicidas, em decorrência da baixa infestação de insetos-praga e plantas daninhas na área experimental.

Foram avaliadas a massa fresca e seca da parte aérea das plantas. Para avaliação da massa fresca, efetuou-se o corte, rente ao solo, na área útil da parcela, aos 105 dias após a emergência (DAE), quando os grãos apresentavam estádio fenólogico $1 / 2$ leitoso e $1 / 2$ farináceo (Velho et al. 2006), com posterior coleta da parte aérea. Para quantificar a produção de massa seca da parte aérea das plantas, utilizou-se uma amostra de $200 \mathrm{~g}$ de massa fresca. O material foi acondicionado em estufa com ventilação forçada, à temperatura de $65^{\circ} \mathrm{C}$, por 72 horas, e, após este período, realizou-se a pesagem, para estimar o teor de umidade das amostras. As plantas foram separadas em colmos, folhas e espigas (milho) ou panículas (sorgo), que foram pesados, separadamente, para determinação da massa fresca, e, em seguida, utilizou-se uma amostra de $200 \mathrm{~g}$ da massa fresca de cada porção, para determinação da massa seca. Os dados foram submetidos a análise da variância e as médias comparadas pelo teste Tukey, a 5\% de probabilidade.

\section{RESULTADOS E DISCUSSÃO}

Houve diferenças significativas, para produção de massa fresca e seca dos híbridos de milho e sorgo. O sorgo 'Volumax' se destacou dos demais tratamentos, em produção de massa fresca e seca, entretanto, não foi constatada diferença estatística na percentagem de massa seca, entre os híbridos de milho e sorgo (Tabela 2).

O sorgo 'Volumax' é, dentre os materiais de sorgo disponíveis, um dos mais utilizados no sudoeste de Goiás, para ensilagem, devido ao alto nível de produção de biomassa. Resultados semelhantes ao deste experimento foram encontrados por Pereira et al. (2007), os quais, avaliando a qualidade nutricional de silagens de milho, produzidas a partir de cinco híbridos (AG-122, AG-9090, AG-5011, Dow-766 e DKB-747), observaram diferenças, quanto ao teor de matéria seca dos mesmos.

Tabela 2. Produção de massa fresca e seca $\left(\mathrm{Mg} \mathrm{ha}^{-1}\right)$ e percentagem de matéria seca da parte aérea de híbridos de milho e sorgo para ensilagem (Rio Verde, GO, 2009).

\begin{tabular}{llll}
\hline \multicolumn{1}{c}{ Híbridos } & $\begin{array}{c}\text { Massa } \\
\text { fresca }\end{array}$ & $\begin{array}{c}\text { Massa } \\
\text { seca }\end{array}$ & $\begin{array}{c}\text { Percentagem } \\
\text { de matéria } \\
\text { seca }\end{array}$ \\
\cline { 2 - 3 } & \multicolumn{2}{c}{$\mathrm{Mg} \mathrm{ha}^{-1}$} & \\
\hline Milho P-30F90 & $61,67 \mathrm{~b}^{1}$ & $16,56 \mathrm{~b}$ & $26,85 \mathrm{a}$ \\
Milho DKB-177 & $50,78 \mathrm{c}$ & $13,15 \mathrm{~cd}$ & $25,90 \mathrm{a}$ \\
Milho AG-7010 & $54,25 \mathrm{bc}$ & $13,90 \mathrm{~cd}$ & $25,62 \mathrm{a}$ \\
Sorgo experimental 1 & $48,79 \mathrm{c}$ & $12,33 \mathrm{~d}$ & $25,27 \mathrm{a}$ \\
Sorgo experimental 2 & $53,16 \mathrm{c}$ & $15,05 \mathrm{bc}$ & $28,31 \mathrm{a}$ \\
Sorgo Volumax & $74,38 \mathrm{a}$ & $20,55 \mathrm{a}$ & $27,63 \mathrm{a}$ \\
\hline Média & 57,17 & 15,26 & 26,60 \\
\hline C.V. (\%) & 5,68 & 7,60 & 7,09 \\
\hline
\end{tabular}

${ }^{1}$ Médias seguidas de letras iguais, na mesma coluna, não diferem entre si, pelo teste Tukey, a 5\% de probabilidade. 
Os materiais de sorgo experimental 1 e sorgo experimental 2, assim como os híbridos de milho DKB-177, AG-7010 e P-30F90, apresentam rendimentos inferiores ao do Volumax. Por isto, é importante detectar o comportamento de híbridos disponíveis no mercado, para que se possa posicionar, nas áreas de produção, os materiais mais responsivos. As silagens de sorgo ou de milho, atualmente, constituem-se entre as principais fontes de volumosos de maior valor nutritivo e bons rendimentos por unidade de área, de boa aceitabilidade pelos animais e de fácil processo operacional para sua colheita e armazenagem (Neumann et al. 2004).

Nas condições deste experimento, houve igualdade estatística na percentagem de massa seca da parte aérea total, entre os híbridos de milho e sorgo, demonstrando, desta forma, que a diferença entre os híbridos testados não está na quantidade total produzida, mas pode ter ocorrido na proporção de algum de seus constituintes (colmo, folhas e panícula ou espiga). Os teores médios de MS das silagens foram, em média, de $27 \%$, portanto, abaixo dos 28 $34 \%$ sugeridos como ideais por McCullough (1977).

Para se obter alta produção de biomassa e elevado valor nutritivo da silagem, é necessário considerar a aptidão e porte da planta, proporção de colmo, folhas e panícula ou espiga e suculência do colmo, entre outras características que variam muito entre os inúmeros materiais disponíveis no mercado (Zago 1997). Houve diferenças significativas para a produção de massa fresca e seca de colmo, folhas e espigas e panículas dos híbridos de milho e sorgo testados (Tabela 3).
Quanto à produção de massa fresca e seca de colmo, folhas e espigas (milho) ou panículas (sorgo) (Tabela 3), observa-se que o sorgo Volumax tem sua produção de biomassa total concentrada nos colmos, enquanto o milho P30F90 apresenta maior biomassa de espigas. Isto é o que confere qualidade à silagem de milho, quando comparado ao sorgo Volumax.

Mello \& Nornberg (2004), avaliando a fração carboidrato e proteína de silagens de milho, sorgo e girassol, afirmam que os componentes estruturais da planta afetam grandemente o fracionamento dos mesmos, afetando, assim, a qualidade nutricional destes materiais. A variação nas frações das plantas, para silagem, em virtude de fatores genotípicos e fenotípicos, tem consequências na produção e composição da planta, com influência direta sobre a qualidade da silagem (Dias 2002). Este mesmo autor, avaliando parâmetros agronômicos de vinte híbridos de milho, verificou que colmo, espigas, grãos e folhas constituem, em média, $56 \%, 27 \%, 35 \%$ e $17 \%$ da planta, respectivamente. $\mathrm{O}$ autor constatou que há grande variação, quanto às frações da planta de milho, entre as cultivares e mesmo dentro das cultivares, devido a vários fatores que atuam sobre a planta, como clima, adubação, fertilidade e tratos culturais.

$\mathrm{Na}$ tentativa de aliar produtividade de matéria seca e valor nutritivo, tem-se procurado desenvolver híbridos de sorgo que tenham equilíbrio entre colmo, folha e panícula e que mantenham valores próximos a $50 \%$ do componente colmo, em relação a folhas e panículas (Brito et al. 1999), para que estes híbridos ou cultivares tenham melhor relação de produção e

Tabela 3. Produção de massa fresca (MF) e massa seca (MS) de colmo, folhas, espigas de milho, panículas de sorgo e percentagem de massa seca de inflorescência, na biomassa total (MSI\%) dos híbridos avaliados (Rio Verde, GO, 2009).

\begin{tabular}{|c|c|c|c|c|c|c|c|}
\hline \multirow{2}{*}{ Híbridos } & \multicolumn{2}{|c|}{ Colmo } & \multicolumn{2}{|c|}{ Folha } & \multicolumn{3}{|c|}{ Inflorescência $^{1}$} \\
\hline & MF & MS & MF & MS & MF & MS & $\mathrm{MSI}^{2}$ \\
\hline & \multicolumn{2}{|c|}{$\mathrm{Mg} \mathrm{ha}^{-1}$} & \multicolumn{2}{|c|}{$\mathrm{Mg} \mathrm{ha}^{-1}$} & \multicolumn{2}{|c|}{$\mathrm{Mg} \mathrm{ha}^{-1}$} & $\%$ \\
\hline Milho P-30F90 & $27,14 \mathrm{c}^{*}$ & $5,11 \mathrm{c}$ & $10,17 \mathrm{ab}$ & $2,91 \mathrm{ab}$ & 24,36 a & $8,55 \mathrm{a}$ & $51,60 \mathrm{a}$ \\
\hline Milho DKB-177 & $23,36 \mathrm{c}$ & $4,30 \mathrm{c}$ & $9,69 \mathrm{~b}$ & $2,48 \mathrm{~b}$ & $17,72 b$ & $6,38 \mathrm{~b}$ & $48,48 \mathrm{a}$ \\
\hline Milho AG-7010 & $23,25 \mathrm{c}$ & $4,00 \mathrm{c}$ & $10,64 \mathrm{ab}$ & $2,68 \mathrm{~b}$ & $20,36 \mathrm{ab}$ & $7,22 b$ & $51,94 \mathrm{a}$ \\
\hline Sorgo experimental 1 & $34,00 \mathrm{~b}$ & $7,77 \mathrm{~b}$ & $9,25 \mathrm{~b}$ & $2,62 \mathrm{~b}$ & $5,54 \mathrm{~d}$ & $1,95 \mathrm{~d}$ & $15,80 \mathrm{~b}$ \\
\hline Sorgo experimental 2 & $33,72 \mathrm{~b}$ & $8,71 \mathrm{~b}$ & $10,39 \mathrm{ab}$ & $3,10 \mathrm{ab}$ & $9,04 \mathrm{~cd}$ & $3,25 \mathrm{~cd}$ & $21,58 \mathrm{~b}$ \\
\hline Sorgo Volumax & $50,83 \mathrm{a}$ & $12,99 \mathrm{a}$ & $13,50 \mathrm{a}$ & $3,99 \mathrm{a}$ & $10,05 \mathrm{c}$ & $3,57 \mathrm{c}$ & $17,37 \mathrm{~b}$ \\
\hline Média & 32,05 & 7,15 & 10,61 & 2,96 & 14,51 & 5,15 & 34,46 \\
\hline C.V. $(\%)$ & 6,90 & 15,46 & 15,15 & 15,95 & 12,98 & 11,23 & 15,98 \\
\hline
\end{tabular}


valor nutritivo (Magalhães et al. 2006). Por outro lado, Magalhães et al. (2006), avaliando a qualidade nutricional de quatro genótipos de sorgo, por meio da técnica in vitro, afirmaram que, entre os genótipos avaliados, o sorgo Volumax possui o maior potencial para produção de silagens.

Deve-se verificar a capacidade de produção da cultivar empregada para silagem e a percentagem de espigas (milho) e panículas (sorgo) na silagem, pois, quanto maior esta proporção, melhor será a qualidade da forragem (Viana \& Noce 2004). A literatura aponta que a participação de grãos pode ser de até $50 \%$ na massa seca (Ferreira 2001, Zeoula et al. 2003). Neste trabalho, a proporção de matéria seca das panículas do sorgo Volumax, na massa total, foi de $17,37 \%$, enquanto o milho P30F90 conferiu 51,94\% de espigas, na biomassa total produzida, resultados próximos aos obtidos por outros autores (Rosa et al. 2004). Diante do exposto, pode-se inferir que o Volumax proporciona maior produtividade de biomassa para silagem, porém, sua qualidade é inferior à do milho P30F90.

\section{CONCLUSÕES}

1. O sorgo Volumax apresentou a maior produção de biomassa, para fins de produção de silagem de planta inteira, sem adubação de nitrogênio em cobertura, na safra de verão, em Goiás.

2. Os híbridos de milho conferiram maior proporção de inflorescência e menor proporção de colmo na biomassa total produzida, quando comparados aos materiais de sorgo. Isto demonstra a importância da utilização de milho para agregar qualidade à produção de silagem de planta inteira.

\section{AGRADECIMENTOS}

Às empresas Monsanto e Pionner, pelo patrocínio das sementes, e ao Conselho Nacional de Desenvolvimento Científico e Tecnológico (CNPq), pela concessão de bolsas PIBIC ao segundo e terceiro autores.

\section{REFERÊNCIAS}

BRITO, C. J. F. A. et al. Anatomia quantitativa e degradação in vitro de tecidos em cultivares de capimelefante. Revista Brasileira de Zootecnia, Viçosa, v. 28, n. 2, p. 223-229, 1999.
DIAS, A. M. A. et al. Efeito do estádio vegetativo do sorgo (Sorghum bicolor (L.) Moench.) sobre a composição química da silagem, consumo, produção e teor de gordura do leite para vacas em lactação, em comparação à silagem de milho (Zea mays L.). Revista Brasileira de Zootecnia, Viçosa, v. 30, n. 6, p. 2086-2092, 2001.

DIAS, F. N. Avaliação de parâmetros agronômicos e nutricionais em híbridos de milho (Zea mays L.) para silagem. 2002. 95 f. Dissertação (Mestrado em Ciência Animal e Pastagens)-Escola Superior de Agricultura Luiz de Queiroz, Universidade de São Paulo, Piracicaba, 2002.

EMPRESA BRASILEIRA DE PESQUISA AGROPECUÁRIA (Embrapa). Centro Nacional de Pesquisa de Solos. Manual de métodos de análise de solo. Rio de Janeiro: Embrapa-CNPS, 1997. (Documentos, 1).

FERREIRA, J. J. Efeito do processamento da planta de milho na qualidade da silagem. In: CRUZ, J. C.; PEREIRA FILHO, I. A.; RODRIGUES, J. A. S. (Eds.). Produção e utilização de silagem de milho e sorgo. Sete Lagoas: Embrapa Milho e Sorgo, 2001. p. 445-472.

MAGALHÃES, R. T. et al. Avaliação de quatro genótipos de sorgo pela técnica "in vitro" semiautomática de produção de gases. Revista Brasileira de Milho e Sorgo, Sete Lagoas, v. 5, n. 1, p. 101-111, 2006.

McCULLOUGH, M. E. Silage and silage fermentation. Feedstuffs, Minneapolis, v. 49, n. 13, p. 49-52, 1977.

MELLO, R. Silagem de milho, sorgo e gramíneas tropicais. Revista Eletrônica Nutritime, Viçosa, v. 1, n. 1, p. 48-58, 2004.

MELLO, R.; NORNBERG, J. L. Fracionamento dos carboidratos de silagens de milho, sorgo e girassol. Ciência Rural, Santa Maria, v. 34, n. 5, p. 1537-1542, 2004.

NEUMANN, M. et al. Avaliação do valor nutritivo da planta e da silagem de diferentes híbridos de sorgo (Sorghum bicolor (L.) Moench.). Revista Brasileira de Zootecnia, Viçosa, v. 31, n. 1, p. 293-301, 2002a.

NEUMANN, M. et al. Avaliação de diferentes híbridos de sorgo (Sorghum bicolor (L.) Moench.) quanto aos componentes da planta e silagens produzidas. Revista Brasileira de Zootecnia, Viçosa, v. 31, n. 1, p. 302-312, 2002b.

NEUMANN, M. et al. Comportamento produtivo e custo de produção de híbridos de sorgo (Sorghum bicolor (L.) Moench.) para silagem. Revista Brasileira de Milho e Sorgo, Sete Lagoas, v. 2, n. 3, p. 43-54, 2003.

NEUMANN, M.; RESTLE, J.; BRONDANI, I. L. Avaliação de silagens de sorgo (Sorghum bicolor (L.) Moench) ou milho (Zea mays L.) na produção do novilho superprecoce. Revista Brasileira de Milho e Sorgo, Sete Lagoas, v. 3, n. 3, p. 438-452, 2004. 
PEREIRA, E. S. et al. Avaliação da qualidade nutricional de silagens de milho (Zea mays L). Revista Caatinga, Mossoró, v. 20, n. 3, p. 8-12, 2007.

ROCHA, F. C. et al. Casca de café em dietas para vacas em lactação: consumo, digestibilidade, produção e composição de leite. Revista Brasileira de Zootecnia, Viçosa, v. 35, n. 5, p. 2163-2171, 2006.

ROSA, J. R. P.; SILVA, J. H. S.; RESTLE, J. Avaliação do comportamento agronômico da planta e valor nutritivo da silagem de diferentes híbridos de milho (Zea mays L.). Revista Brasileira de Zootecnia, Viçosa, v. 33, n. 2, p. 302-312, 2004.

SILVA, J. M. Silagem de forrageiras tropicais. 2001. Disponível em: <http://www.cnpgc.embrapa.br/ publicacoes/divulga/GCD51.html $>$. Acesso em: 22. jul. 2007.

SILVA, J. M. et al. Desempenho animal e avaliação do potencial produtivo de forragens para ensilagem, por intermédio de diferentes fontes de suplementação nitrogenada. Revista Brasileira de Zootecnia, Viçosa, v. 28, n. 3, p. 642-653, 1999.
VELHO, J. P. et al. Alterações bromatológicas nas silagens de milho submetidas a crescentes tempos de exposição ao ar após “desensilagem”. Ciência Rural, Santa Maria, v. 36, n. 3, p. 916-923, 2006.

VIANA, A. C.; NOCE, M. A. Avaliação da capacidade de produção de silagem de cultivares de milho e sorgo desenvolvidas pela Embrapa, no Estado de Minas Gerais. 2004. Disponível em: <http:/www.cnpms.embrapa.br/ publicacoes/publica/Doc31.pdf $>$. Acesso em: 22. jul. 2007.

ZAGO, C. P. Utilização do sorgo na alimentação de ruminantes. In: Manejo cultural do sorgo para forragem. Sete Lagoas: Embrapa-CNPMS, 1997. p. 9-26. (Circular técnica, 17).

ZEOULA, L. M. et al. Avaliação de cinco híbridos de milho (Zea mays L.) em diferentes estádios de maturação. Revista Brasileira de Zootecnia, Viçosa, v. 32, n. 3, p. 556566, 2003. 